\title{
APROXIMAÇÕES AO MÉTODO DE MÉSZÁROS: NOTAS SOBRE O LIVRO O CONCEITO DE DIALÉTICA DE LUKÁCS, DE 1970
}

\author{
Demetrio Cherobini ${ }^{1}$
}

\begin{abstract}
RESUMO
Este artigo analisa o ensaio "O conceito de dialética de Lukács", publicado por István Mészáros em 1970. Investiga, basicamente, os elementos de argumentação e de crítica realizados por Mészáros a respeito das contradições e dos pressupostos teóricos e políticos contidos na obra de seu velho mestre e amigo. Analisa, também, elementos concernentes ao método utilizado por Mészáros em seu procedimento de escrutínio crítico da teoria de Lukács, método este já desenvolvido em estudos anteriores e que será retomado em momentos posteriores de seu itinerário intelectual. Tal método consiste em, ao se tomar como objeto de investigação a obra total de determinado autor que se queria conhecer, não separar rigidamente os diferentes momentos dessa obra. Assim, constata-se que o essencial, nesse tipo de pesquisa, é considerar as elaborações teóricas - expressas em distintos momentos de uma trajetória intelectual - como um todo dinâmico, a fim de se poder captar o aí "núcleo organizador" da complexa elaboração conceitual. A ideia fundamental presente na obra global de um autor passa, de fato, por inúmeras mutações ao longo dos anos. Sua forma se altera em razão das transformações históricas e das novas respostas que o intelectual fornece aos desafios com os quais se depara. Mas ela permanece como um fio subterrâneo que interliga os vários momentos de sua produção intelectual, a ponto de lhe assegurar a unidade fundamental. O que ocorre, então, é uma mudança qualitativa que, evidentemente, se traduz numa nova forma de teorização por parte do autor em questão. Tal mudança qualitativa diz respeito à totalidade do desenvolvimento do seu pensamento, em contraposição às mudanças que ocorrem apenas em certos pontos e aspecto desse desenvolvimento. Fornecer pistas para o entendimento desse método usado por Mészáros é o que visamos com o presente artigo.
\end{abstract}

Palavras-chave: Mészáros. Ontologia. Crítica. Dialética.

\begin{abstract}
S
The following paper analyzes the essay "Lukács' concept of dialetics", published by István Mészáros in 1970. It basically goes through the elements of argumentation and criticism made by Mészáros about the contradictions and theoretical and political assumptions contained in the work of his old friend and master. It also analyzes elements concerning the method used by Mészáros in his critical scrutiny procedure of Lukacs's theory, this method already developed in previous studies, which will be taken up in later moments of his intellectual itinerary. The method includes, in taking into consideration the total research object of a piece of work by a particular author who wanted to know, not rigidly separate the different moments of the work. Thus, it seems that the essential approach in this type of research is to consider the theoretical elaborations - expressed at different times of an intellectual trajectory - as a dynamic whole, in order to be able to capture the "organizer core" of the complex conceptual elaboration. The fundamental idea in this global work of an author passes, in fact, by a number of changes throughout the years. Its shape changes as a result of historical developments and new answers that provide intellectual challenges that are faced. Although it
\end{abstract}

\footnotetext{
${ }^{1}$ Doutor em Educação pela Universidade Federal de Santa Catarina - (UFSC). E-mail: cherobini@yahoo.com.br
} 
remains an underground wire that connects the various moments of his intellectual production, as to assure the fundamental unit. What happens, then, is a qualitative change, translating into a new way of theorizing by the author in question. Such qualitative change concerns the entire development of his thought, as opposed to changes that occur only at certain points and aspects of this development. Providing clues to the understanding of this method used by Mészáros is what we aim at this research.

Keywords:: Mészáros. Ontology. Critical. Dialetics.

\section{INTRODUÇÃO}

Mais honra meu estilo quem aprende como superar o mestre. Walt Whitman

István Mészáros é um autor notável, em nosso tempo histórico, por desenvolver uma teoria que, com todo seu vigor crítico e densidade, provoca polêmica no interior do campo marxista. Seu objetivo - como se depreende de seu livro principal ${ }^{2}$ - é o de, retomando o pensamento de Marx, ir além do capital, tanto como conceito, conforme delineado na obra madura e inacabada do filósofo alemão, quanto como relação social sistematicamente controladora do metabolismo social humano. Por essas razões, para muitos dos que têm em alta conta as formulações contidas especialmente em $O$ Capital, os escritos do filósofo húngaro são vistos com apreensão, dúvidas e reticências ${ }^{3}$.

Não entraremos, por enquanto, diretamente, na polêmica sobre o conceito de capital que se desdobra nos conceitos de crise estrutural e de transição socialista ${ }^{4}$. O que nos interessa, no momento, é compreender traços fundamentais do pensamento de Mészáros que, uma vez detectados, podem servir para o entendimento de suas formulações mais complexas, tais como as que aparecem em Para além do capital: rumo a uma teoria da transição. Mais precisamente, propomo-nos a, dentro dos limites deste artigo, identificar elementos de seu método de pesquisa e alguns aspectos de sua forma peculiar de elaboração teórico-crítica ${ }^{5}$.

\footnotetext{
${ }^{2}$ MÉSZÁROS, István. Para além do capital: rumo a uma teoria da transição. São Paulo: Boitempo, 2002.

${ }^{3}$ Por exemplo, nosso professor e amigo José Martins, da Universidade Federal de Santa Catarina e do 13 de Maio Núcleo de Educação Popular, que descarta por completo as formulações do, segundo suas palavras, "eclético sociólogo húngaro". Ver, a esse respeito: MARTINS, José. Império do terror: Estados Unidos, ciclos econômicos e guerras no início do século XXI. São Paulo: Editora Instituto José Luís e Rosa Sundermann, 2005.

${ }^{4}$ Ademais, o tema da pesquisa que ora realizamos, em nível de doutorado, junto ao Programa de Pós-Graduação em Educação da Universidade Federal de Santa Catarina, sob a orientação do Prof. Dr. Paulo Sérgio Tumolo, tem por objetivo, justamente, compreender o conceito de capital na obra de Mészáros. Os resultados dessa investigação serão publicizados no seu devido tempo.

${ }^{5}$ Esse tema já foi explorado por nós, sumariamente, em nossa dissertação de mestrado. Ver: CHEROBINI, Demetrio. Educação e política no pensamento de István Mészáros: estudo introdutório. Florianópolis, SC: 2010. Dissertação (mestrado) - Universidade Federal de Santa Catarina, Centro de Ciências da Educação. Programa de Pós-Graduação em Educação.
}

\begin{tabular}{|c|c|c|c|c|}
\hline Rovista Dialectus & Ano 2 & n.7 & Setembro-Dezembro 2015 & p. $35-47$ \\
\hline
\end{tabular}


Nesse intento, partimos de certos pressupostos. O primeiro é o de que o filósofo húngaro se propõe objetivos ousados: atualizar a "arma da crítica", isto é, a teoria revolucionária de Marx; decifrar o capital tal como ele se configura em nosso tempo histórico; extrair daí uma estratégia capaz de orientar as lutas dos trabalhadores na direção da emancipação humana; entre outros. O segundo é o de que as possibilidades de atualização de uma teoria revolucionária acerca do ser social, bem como a extração de suas implicações estratégico-políticas, são determinadas, em larga medida, pelas condições históricas estabelecidas e pela forma como o pesquisador/formulador se insere nessa processualidade. Mas isso também tem a ver como o modo eminentemente teórico com que ele procede no sentido de dialogar criticamente com a tradição passada, investigar o real e expressar, nesse movimento, por meio de um sistema conceitual próprio, a dinâmica sócio-histórica concreta na qual se situa e guarda uma posição específica.

A esse respeito, cremos que elementos importantes sobre o modo de proceder teóricometodológico do pensador húngaro podem ser encontrados em seu ensaio $O$ conceito de dialética em Lukács ${ }^{6}$, escrito entre 1967 e 1968, publicado originalmente em 1970 e lançado no Brasil apenas recentemente ${ }^{7}$.

Em si mesma, a obra consiste numa apresentação crítica introdutória - "breves esboços", dirá, modestamente, Mészáros - do conceito de dialética de Lukács, mostrando as tensões, contradições, os elementos de continuidade e descontinuidade e a "idéia sintetizadora fundamental" que perpassam as formulações teóricas do velho filósofo húngaro ao longo das várias etapas de formação do seu pensamento. Mas, além de revelar traços essenciais das concepções de Lukács, o livro também é um registro ímpar do modo de pensar do próprio Mészáros, que, na época, já demonstrava ser um pensador incisivo e com grande capacidade de penetração analítica e de autonomia intelectual ${ }^{8}$.

\footnotetext{
${ }^{6}$ MÉSZÁROS, István. O conceito de dialética em Lukács. $1^{\text {a }}$ ed. - São Paulo: Boitempo, 2013.

${ }^{7} \mathrm{Na}$ bela Apresentação que escreve para esse ensaio, José Paulo Netto afirma que, em relação ao método utilizado, Mészáros inaugura uma matriz interpretativa da teoria lukacsiana, constituindo-se assim em "um dos melhores e mais criativos estudos já publicados" sobre a concepção de dialética do velho filósofo húngaro. A originalidade dessa matriz interpretativa reside no modo específico como Mészáros aborda a obra de Lukács, tomando-a em seu todo, em seus momentos constitutivos substanciais, "menos como repertório de soluções (interpretando sistematicamente tal obra como respostas expressivas a questões histórico-sociais determinadas e relevantes) e mais como constelações teóricas problematizantes e problemáticas. (...) É essa perspectiva de Mészáros que lhe permite agarrar a obra de Lukács na sua originalidade, destacar a sua monumentalidade e, no mesmo andamento perquiridor, apontar as suas tensões irresolutas e indicar a sua problematicidade, instaurando um espaço de crítica a Lukács que, mantendo uma relação empática e simpática com sua obra, atinge de modo criativo e tendencialmente superador os seus fundamentos e o seu âmbito de validez" (2013, p. 13-4).

${ }^{8}$ Lembremos que o texto, com fortíssimo acento crítico, foi publicado quando Lukács ainda era vivo.
} 
A revelação de pensamento de Mészáros se dá, então, por meio da crítica do conceito de dialética de Lukács. A abordagem mészáriana leva em conta, aqui, a obra global do autor investigado, tomando-a como uma realidade em movimento e que, por esse motivo, precisa ser compreendida dinamicamente. Esse método permite apreender os elementos de continuidade e descontinuidade da obra perquirida, e, também, além disso, aquilo que Mészáros chama de "ideia sintetizadora fundamental", isto é, a fonte teórica da organização das formulações do autor estudado. Tal procedimento possibilita, assim, vislumbrar as tensões e as contradições não resolvidas presentes na teoria em questão: como elas se formam, se estruturam, se transformam (numa escala temporal que pode ser mais ou menos longa), como se desenvolvem em sua totalidade. Tudo isso, evidentemente, levando-se em consideração a situação histórica do intelectual analisado, como ele se insere em seu contexto, vive as transformações de seu tempo e as expressa em seus constructos intelectuais.

Desse modo, o método de Mészáros exige a não separação rígida entre os diferentes momentos da obra de um pensador. O essencial, na investigação, é considerar suas elaborações como um todo dinâmico, a fim de se poder captar o "núcleo organizador" dessa formulação teórica. Nas palavras do filósofo húngaro:

\begin{abstract}
Os principais contornos de uma ideia podem - e devem - estar presentes na mente do filósofo quando ele elabora, em um texto específico, algumas de suas implicações concretas em contextos particulares. Essa ideia pode passar, é claro, por mudanças significativas; os próprios contextos particulares requerem constantes reelaborações e modificações em consonância com as características específicas das situações concretas que têm de ser levadas em conta. Mas até mesmo uma conversão genuína do 'idealismo' para o 'materialismo' não implica necessariamente uma rejeição ou repressão radical da ideia sintetizadora original. (MÉSZÁROS, 2013, p. $33)$.
\end{abstract}

Essa concepção é central para Mészáros. A ideia sintetizadora fundamental de um autor já é discernível em estágios ainda iniciais da formação de seu pensamento. A despeito das modificações significativas que nela se verifiquem ao longo do tempo, não ocorrem rupturas absolutas. Essa ideia fundamental passa, de fato, por mutações. Sua forma se altera constantemente em razão das transformações históricas e das novas respostas que o intelectual fornece aos desafios com que se depara. Mas ela permanece como um fio subterrâneo que interliga os vários momentos de sua produção intelectual a ponto de lhe assegurar a unidade.

A obra de Lukács é, nesse contexto, um bom exemplo disso. Seus escritos, tanto os do período “idealista”, quanto os do marxista, revelam, segundo Mészáros, a mesma idéia sintetizadora fundamental, isto é, "a mesma estrutura de pensamento, embora ele tenha

\begin{tabular}{|l|l|l|l|l|}
\hline Govista Oialectus & Ano 2 & n.7 & Setembro-Dezembro 2015 & p. $35-47$ \\
\hline
\end{tabular}


genuinamente deixado para trás seus posicionamentos idealistas originais" (Mészáros, 2013, p. 33). Ou seja: Lukács mudou radicalmente a orientação de seu pensamento - do idealismo para o materialismo marxista, após a Revolução Russa de 1917 -, seu pensamento teve inflexões profundas, mas a "ideia sintetizadora fundamental", a despeito da nova forma que adquiriu, manteve certa estrutura que se revelaria essencialmente contraditória ao longo dos anos.

Preservou-se, dessa maneira, portanto, a unidade do pensamento lukacsiano. Mas, é necessário frisar, tal unidade é radicalmente dialética, apresenta continuidades e descontinuidades, num processo cujo sentido é “a 'suprassunção' (Aufhebung) de um estágio anterior em uma complexidade cada vez maior" (Idem). Mészáros explica que é impossível ocorrer originalidade sem haver essa unidade do pensamento em sua estrutura geral. Pois a originalidade, que equivale a uma determinada síntese, é sempre calcada numa síntese anterior, que é, precisamente, a ideia fundamental, ou seja, "a síntese original que [...] estruturou [o pensamento do filósofo], dialeticamente, em todas as suas sucessivas modificações" (Ibid., p. 34). A "ruptura radical” com o passado é, na visão de Mészáros, apenas aparente. Ela só pode ser, na verdade, uma ruptura parcial ${ }^{9}$.

O que ocorre, então, de fato, é uma mudança qualitativa que, evidentemente, se traduz numa nova forma de teorização por parte do autor em questão. Tal mudança qualitativa diz respeito à totalidade do desenvolvimento do seu pensamento, em contraposição às mudanças que ocorrem apenas em certos pontos e aspectos desse desenvolvimento. Ruptura total, por sua vez, é algo bastante duvidoso no entender do filósofo húngaro. Nesse sentido, explica Mészáros:

A identificação de Lukács com o marxismo significou uma mudança qualitativa em seu desenvolvimento. No entanto, ela não aconteceu da noite para o dia; não poderia ser descrita com as categorias de 'ruptura radical' e 'radicalmente nova', contra as quais Lukács, em sua defesa da dialética, travou uma batalha durante toda a sua vida. Ao contrário, as raízes dessa mudança devem ser buscadas muito antes, em sua síntese dialética na juventude e nas tensões internas desta"10. (MÉSZÁROS, 2013, p. 34 ).

\footnotetext{
${ }^{9}$ Mészáros faz questão de citar, aqui, a título de ilustração, o caso das obras de Hegel, Marx, Lukács e Sartre Marx, por exemplo, sempre foi um revolucionário, mesmo antes de ser um filósofo materialista e de ter elaborado a sua própria filosofia.

${ }^{10}$ Segundo Mészáros, Lukács faz parte de um seleto grupo de "homens significativos" capazes de viverem e pensarem seu tempo, isto é, sujeitos para quem pensar e viver não são processos incongruentes, e sim conectados e integrados num mesmo movimento, ainda que, em meio a esse processo, possam apresentar tensões e contradições. Em tais pessoas, pensamento e ser estão em comunicação direta e em consonância com a situação histórica em que vivem, embora nem sempre elas sejam capazes de acompanhar, com a devida velocidade, as mudanças históricas que experimentam. Tais "homens significativos", diz Mészáros, não aprendem nos livros as questões importantes de sua época: eles as vivem. As influências intelectuais que 
Calcado nesses pressupostos, Mészáros se põe a analisar o devir do pensamento de Lukács e aí descobre, justamente, a "ideia sintetizadora fundamental”, que confere unidade à sua obra global: a dualidade entre dever-ser (Sollen) e ser (Sein) ${ }^{11}$. O Lukács da fase de juventude ${ }^{12}$, por exemplo, criticou a profunda crise da burguesia e sua cultura em geral e polemizou contra o programa de "atualização" da sociedade capitalista húngara. Mas qual era o sentido de tais críticas e polêmicas? Meras denúncias da realidade existente e apelos ao "dever-ser" abstratos. Em suma: desejo, esperança e sonho de uma nova sociedade para os húngaros.

Mészáros explica que a perspectiva filosófica e política de Lukács mudou significativamente com a passagem dos acontecimentos revolucionários dos anos 1917 e 1918. Entretanto, a contradição estrutural da sua "ideia sintetizadora fundamental" - a dualidade entre ser e dever-ser - se manteve, embora metamorfoseada. Tal mudança de perspectiva foi gradativa e relativa. Mesmo identificando-se com o marxismo, "o interesse pelo 'dever-ser' e a enunciação de alternativas dramáticas não foram abandonadas por Lukács" (Ibid., p. 39). A aposta no “dever-ser” foi transposta, em verdade, a um outro nível. História e consciência de classe, publicada em 1923, é a obra que Mészáros identifica, em seu ensaio, como sendo a que melhor expressa esse período transitório de Lukács.

Mészáros mostra que a contradição essencial da formulação lukacsiana, longe de ser eliminada, ganhou uma nova forma, determinada pelo contexto no qual, passados os eventos revolucionários, a Hungria não verificava em seu interior "nenhum agente social poderoso que pudesse materializar as mudanças desejadas e defendidas" (Ibid., p. 40) pelo filósofo húngaro. Tal "vácuo sociopolítico" acabou por marcar a filosofia de Lukács. A inexistência de mediações concretas materiais capazes de fazer a transição do velho para o novo se expressou inevitavelmente no plano de suas ideias, produzindo aí uma incisiva exortação do "dever-ser", isto é, petições ético-morais em favor de um mundo novo a se confrontar com o ser real da sociedade húngara, num contexto marcado pelo atraso histórico e pela imobilidade.

recebem, nesse devir, são colhidas e moldadas "em um todo coerente que lhes é próprio" (Ibid., 35). Essas influências exercem, por certo, efeitos na orientação posterior do filósofo, mas elas, por sua vez, são condicionadas pela situação histórica, que é o elemento preponderante nessa relação. Assim, complementa o pensador húngaro: "O que separa o filósofo importante do eclético inteligente é a irrelevância histórica da síntese puramente acadêmica do segundo, quando comparada à máxima importância prática do primeiro" (Idem).

${ }^{11}$ José Paulo Netto, pertinentemente, explica que tal dualidade "poderia ser enunciada como entre dever-ser $e$ prática social objetivamente viável (ou também, entre imperativo para realizar uma vida humana plena de sentido e facticidade histórica)" (2013, p. 18).

12 Mészáros está falando, aqui, do período pré-marxista de Lukács, onde se destacam as obras A alma e as formas, Cultura estética e A teoria do romance.

\begin{tabular}{|l|l|l|l|l|}
\hline Q & Ano 2 & n.7 & Setembro-Dezembro 2015 & p. $35-47$ \\
\hline
\end{tabular}


Lukács, então, que visava traduzir suas aspirações políticas num programa prático factível, viu-se obrigado a se aliar ao comunismo internacional, num momento, frise-se, em que esse movimento estava se tornando cada vez mais dominado pelo stalinismo. Inevitavelmente, a situação histórica concreta trouxe consequiências - problemáticas - para sua teoria, mas, paradoxalmente, possibilitou ao filósofo elaborar e enriquecer categorias filosóficas de tremenda importância, tais como totalidade e mediação.

Lukács via-se agora imerso em uma nova realidade, também contraditória, na qual era impelido a pensar sobre as possibilidades de se superar a lacuna existente entre o processo revolucionário tal como acontecia na União Soviética e as perspectivas universais do socialismo em geral. Nesse contexto, Meszáros afirma que Lukács tentou "a tarefa impossível" de resolver o problema da separação entre tais pólos: "Ele dedicou as suas maiores energias para elaborar aquelas 'mediações' que deveriam preencher a lacuna. (As numerosas obras que escreveu ao longo do interminável confronto com o problema da mediação só adquirem seu significado pleno nessa conexão.)". (Ibid., p. 43).

Tal como Thomas Mann, escritor de sua mais alta estima, Lukács sentia o mesmo desejo de unidade e síntese objetiva em um mundo em que a distância entre "intenção e resultado" parecia aumentar a toda hora. Mészáros explica que esse "desafio programático" será o "fator estruturante essencial de seu pensamento pelo resto de sua vida" (Ibid., p. 46). A contradição inerente ao pensamento de Lukács se tornará mais ricamente determinada com o passar dos anos, mas não deixará de existir nas obras de maturidade, onde o dever-ser (Sollen) acabará tomando a forma do "trabalho da consciência sobre a consciência", como condição para as soluções objetivas acerca das alternativas de caminhos para a história.

Feitas as colocações demarcativas dos elementos de continuidade presentes no longo desenvolvimento intelectual de Lukács, Mészáros passa a analisar os traços de descontinuidade existentes em sua obra. $\mathrm{O}$ texto que introduz mudanças decisivas, nesse sentido, é o já mencionado História e consciência de classe, no qual os temas da totalidade e da mediação ganham pleno destaque. Nesse livro, lemos, por exemplo, que:

"Não é o predomínio de motivos econômicos na explicação da história que distingue de maneira decisiva o marxismo da ciência burguesa, mas o ponto de vista da totalidade. A categoria da totalidade, o domínio universal e determinante do todo sobre as partes, constitui a essência do método que Marx recebeu de Hegel e transformou de maneira original no fundamento de uma ciência nova.” (Lukács, apud Mészáros, Ibid, p. 46).

\begin{tabular}{|c|l|l|l|l|}
\hline Govista & Ano 2 & n.7 & Setembro-Dezembro 2015 & p. $35-47$ \\
\hline
\end{tabular}


Mészáros explica que o "ponto de vista da totalidade", aqui, ainda é uma posição abstrata, mas permite a Lukács elaborar a ontologia social que fundamentará seu famoso livro de 1923, na qual “a totalidade concreta é (...) a categoria fundamental da realidade” (Lukács, apud Mészáros, ibid., p. 58), isto é, a categoria que concretiza a realidade como processo histórico-social.

E para que a totalidade social possa ser, justamente, apreendida em sua concretude, faz-se necessária a presença de outra categoria decisiva: a mediação. A totalidade social existe por e nas mediações multiformes por meio das quais as "totalidades parciais" se interligam umas às outras "em um complexo dinâmico geral que se altera e modifica o tempo todo" (Mészáros, ibid., p. 58). Segundo Mészáros, foi o encontro com o marxismo que “esclareceu [para Lukács] o fato de que a ligação intermediária crucial de todos os fenômenos humanos é a 'atividade crítico-prática' do homem, com sua referência final - uma referência 'em última análise' - à esfera da economia” (Ibid., p. 61, grifo nosso). A questão teórica decisiva para os revolucionários é, nesse contexto, compreender a complexidade dessa "ligação intermediária crucial" materializada, justamente, num intrincado sistema de mediações.

Cabe esclarecer que o papel da economia não é, aqui, mecânico nem determinista, mas dialético e ativo. A economia é, em última instância, o sistema de referência estrutural e metodológico. Nesse sentido, ela só adquire verdadeiro significado na medida em que formos capazes de compreender "as mediações multiformes específicas nos mais variados campos da atividade humana, que, além de serem 'baseadas' em uma 'realidade econômica', também estruturam ativamente essa realidade por meio de sua estrutura própria, extremamente complexa e relativamente autônoma" (Ibid., p. 61-2).

Assim, prossegue Mészáros, na visão de Lukács, a compreensão da noção marxiana de economia depende de nossa capacidade de apreender dialeticamente a multiplicidade de mediações que possibilitam e condicionam a produção e a reprodução da vida humana em sociedade. A economia, nesse contexto, é "determinante último" e, ao mesmo tempo, “determinante determinado". Ela não existe fora do complexo dinâmico de mediações concretas que lhe dão forma e substância - mesmo as mediações mais "espirituais" existentes na sociedade devem ser consideradas. Seguindo Marx, nesse contexto, Lukács entenderá que a economia é a "compreensão dialética de todas as categorias da sociedade humana, por meio de suas transformações complexas na história" (Ibid., p. 62).

\begin{tabular}{|c|l|l|l|l|}
\hline Govista & Ano 2 & n.7 & Setembro-Dezembro 2015 & p. $35-47$ \\
\hline
\end{tabular}


Temos aí uma noção da profunda e rica concepção de mediação e de totalidade (dialética) de Lukács. Mas, diz Mészáros, apesar de sua qualificada elaboração, ela foi - como não poderia deixar de ser - afetada pela situação histórica do autor como crítico, político e filósofo. Depois de reconhecer as grandes conquistas do mestre - suas formulações nos campos da epistemologia, ética, ontologia e filosofia da história -, o discípulo não deixa de apontar os seus problemas. Diz ele, com ousadia: "a natureza teórica geral dessa concepção da mediação se torna uma armadilha autoimposta em determinadas situações” (Ibid., p. 63). Claro está que tal conceito de mediação precisa ser compreendido "nos termos da vida do filósofo e de suas interações com o sistema de suas idéias" (Ibid., p. 64, grifos nossos). Conforme explica Mészáros:

Os limites das realizações filosóficas de Lukács são estabelecidos por sua própria concepção de mediação ou, para ser mais preciso, pelos defeitos dessa concepção: pela intrusão injustificável da 'imediaticidade' em sua visão geral de mundo. Isso pode ser visto claramente (...) na transferência direta de um padrão social particular para um nível histórico-social mais geral. (MÉSZÁROS, 2013, p. 64, grifo nosso).

Pergunta-se, então, Mészáros: por que a intrusão da imediaticidade ocorre, apesar da consciência e do refinamento teórico de Lukács acerca do tema das mediações? A resposta reside no caráter abstrato da dimensão política da concepção lukacsiana de mediação. Nesse sentido, é preciso, como dissemos, analisar a relação de tais concepções com a situação vivida pelo filósofo, isto é, o contexto histórico que afetou suas idéias e que teve como “"übergreifendes Moment' (...) a mudança fundamental no movimento socialista internacional na década de 1920, seguindo as mudanças no desenvolvimento interno soviético como resultado da vitória de Stalin" (Ibid., p. 65).

Mészáros (Idem) sublinha, também, como elemento histórico determinante a funcionar como quadro de referência para as formulações lukacsianas:

[...] a desintegração prática de todas as formas de mediação política eficaz, desde os conselhos operários até os sindicatos. E mesmo o partido, no decorrer da adaptação às exigências das políticas stalinistas, perdeu amplamente sua função e seu potencial mediador. Se a ideia de Lukács a respeito do partido, formulada em Historia e consciência de classe, continha muita idealização, essa idealização se tornou opressiva em outras circunstâncias. Sobretudo porque, em Historia e consciência de classe, a instituição dos conselhos operários ainda aparecia como forma necessária de mediação e de instrumentalidade efetiva. Agora, no entanto, seu lugar ficou vazio, assim como tiveram de deixar um vácuo atrás de si todas as outras formas de mediação política. Nesse aspecto, a década de 1920 não apenas

\begin{tabular}{|c|l|l|l|l|}
\hline Govista & Ano 2 & n.7 & Setembro-Dezembro 2015 & p. $35-47$ \\
\hline
\end{tabular}


deu origem a uma evolução política, como marcou inequivocamente uma fase de involução no realismo político". (MÉSZÁROS, 2013, p. 65).

Assim, com a mudança no desenvolvimento do movimento comunista internacional nos anos 1920, cada vez mais organizado pelo stalinismo, as formas de mediação política capazes de levar adiante um projeto de transição socialista desapareceram ou perderam sua efetividade e potencialidade revolucionárias. O espaço para essa mediação, no plano do real, ficou vazio. Lukács, nesse contexto, ao comprar a idéia do "socialismo num só país" (mesmo sem ser stalinista), sofreu efeitos dessa situação em suas formulações teóricas. De que maneira? Explica Mészáros (Ibid., p. 65-6):

Como os intermediários políticos - e as garantias instrumentais - estão ausentes, a lacuna entre a imediaticidade das realidades sociopolíticas e o programa geral do marxismo tem de ser preenchida pela atribuição do papel de mediação à ética (grifo nosso), pela afirmação de que 'a ética é uma ligação intermediária crucial em todo o processo'. Portanto, a ausência de forças mediadoras eficazes é 'remediada' por um apelo direto à 'razão', à 'responsabilidade moral' do homem, ao 'pathos moral da vida', à 'responsabilidade dos intelectuais' etc., de modo que - por mais paradoxal que pareça - Lukács se encontre, nesse aspecto, na posição de 'utopismo ético', apesar de suas repetidas polêmicas contra este, e apesar de sua clara percepção de que as raízes intelectuais do utopismo ético podem ser localizadas na falta de mediações. (A significativa superestimação de Lukács do papel dos intelectuais na sociedade contemporânea pertence ao mesmo complexo de problemas.)

(...) Desse modo, a abstratividade da dimensão política na concepção que temos desse sistema de mediações dialético deixa suas marcas nos vários complexos de problemas, embora, é claro, não da mesma maneira e no mesmo grau, seja na estética, na ontologia, na epistemologia ou na própria ética à qual é atribuída o papel problemático da 'mediação suposta'. (MÉSZÁROS, 2013, p. 65-6).

É essa intrusão da "imediaticidade" que, segundo Mészáros, confere abstratividade a algumas das análises que Lukács faz da realidade social e política de seu tempo. Vale a pena analisar, brevemente, nesse sentido, o caso da crítica lukacsiana ao jdanovismo, marcada, justamente, pelas contradições das concepções políticas de mediação do filósofo húngaro. Apesar de longa, é importante transcrever mais uma passagem esclarecedora de $O$ conceito de dialética de Lukács:

[...] parece inconsistente da parte de Lukács que, apesar de condenar o jdanovismo e sua teoria 'não mediada' do 'romantismo revolucionário', ele aceite a instrumentalidade estreita e não mediada que necessariamente $o$ produz. Suas análises desse fenômeno cultural-ideológico permanecem inevitavelmente abstratas no sentido de que os determinantes sociais concretos do jdanovismo não podem ser revelados. $\mathrm{O}$ discurso é limitado à

\begin{tabular}{|c|l|l|l|l|}
\hline Govista Qialectus & Ano 2 & n.7 & Setembro-Dezembro 2015 & p. $35-47$ \\
\hline
\end{tabular}


esfera ideológica, e às vezes as relações causais efetivas ainda são invertidas: é como se as aberrações e contradições do nível ideológico fossem responsáveis pelos males do desenvolvimento social e, portanto, os remédios devessem ser encontrados nesse nível, por meio de uma intensa clarificação ideológica. [...]

[Desse modo,] a ausência efetiva de instituições e forças mediadoras sociopolíticas no desenvolvimento soviético afetou muito as perspectivas de Lukács, destruindo a possibilidade de uma crítica prático-política: a partir do fim da década de 1920, a crítica estava condenada a se tornar teórico-abstrata [...]. (MÉSZÁROS, 2013, p. 66-8, grifo nosso).

Como mencionamos antes, suas perspectivas foram caracterizadas por uma dualidade, na forma de ligação das questões cotidianas com os objetivos gerais mais amplos de uma humanidade socialista. Nessa dualidade de perspectivas, o fator dominante nunca deixou de ser a defesa incessante - por mais que fosse 'fundada no dever-ser' - dos valores e dos objetivos socialistas finais. Por mais que tenha conferido um caráter abstrato a muitas de suas análises, isso permitiu também que ele mantivesse vivos, com grande rigor intelectual, os ideais socialistas e os usasse no quadro geral da crítica do imediatamente dado."

A crítica de Mészáros, aqui, é acompanhada de um generoso reconhecimento. A dualidade presente na obra de Lukács trouxe consequências problemáticas para muitas de suas concepções. No entanto, também foi o motor para que o velho filósofo húngaro desenvolvesse de maneira ímpar a teoria marxista.

\section{CONCLUSÃO: MÉTODO, CONTINUIDADE E DESCONTINUIDADE NA OBRA GLOBAL DE MÉSZÁROS}

Em seu ensaio da década de 1960, Mészáros realiza uma primeira tentativa de balanço crítico da obra de György Lukács. Nesse texto, como dissemos acima, ficam bastante claros elementos centrais de seu método de trabalho: considerar a obra global do autor estudado; analisar os elementos de continuidade e descontinuidade ao longo da formação dessa obra; captar a "ideia sintetizadora fundamental", que organiza e confere unidade a tais formulações a despeito de suas modificações significativas; compreender a relação do autor em questão com as formas sociais de seu tempo histórico; verificar como esse tempo é apropriado teoricamente e se sedimenta em seus constructos intelectuais. Ao fazer isso, o autor de $O$ conceito de dialética em Lukács identifica na obra de seu mestre uma dualidade estrutural fundamental, entre ser (Sein) e dever-ser (Sollen), presente já nos anos de juventude, no assim chamado período "idealista", mas que persiste na fase de maturidade, marxista, expressando a

\begin{tabular}{|c|l|l|l|l|}
\hline Govista Dialectus & Ano 2 & n.7 & Setembro-Dezembro 2015 & p. $35-47$ \\
\hline
\end{tabular}


seu modo certas contradições cultivadas por Lukács - a intrusão da imediaticidade -, que se fundam, em última instância, na dimensão política de seu conceito de mediação.

Na medida em que esse método será retomado em anos subseqüentes, constituindo-se mesmo numa constante em sua obra, cremos poder assinalar aí um dos elementos de continuidade presentes na obra global de Mészáros. Tal procedimento se revelará fundamental para o projeto embasador de sua obra maior, Para além do capital: rumo a uma teoria da transição, onde o debate com a obra de Lukács - e, também, com a de Marx - será retomado de maneira exaustiva e criativa para a análise e teorização sobre o desenvolvimento do capital em suas condições de efetivação no século XX. Dessa forma, por lançar luzes valiosas para o entendimento de escritos posteriores de Mészáros, cremos poder afirmar que O conceito de dialética em Lukács se revela, não como um escrito marginal, e sim central para a compreensão do pensamento do filósofo húngaro, bem como de sua obra global.

Cabe destacar, por fim, um elemento de descontinuidade nessa obra global, um postulado mészáriano que aparece em $O$ conceito de dialética em Lukács e que, salvo engano de nossa parte, está ausente em momentos posteriores da sua teorização: após fazer a crítica impiedosa das contradições de Lukács a respeito das suas propostas para se levar o socialismo adiante, Mészáros conclui seu ensaio com uma afirmação marcante: “a tarefa [para se superar os impasses da sociedade socialista] é uma democratização e uma reestruturação radical de todas as estruturas sociais, e não o reagrupamento utópico das hierarquias existentes" (Ibid., p. 70, grifo nosso).

Seria, aqui, a posição de Mészáros, no que toca à democratização, próxima da que mantinha Lukács na época? José Paulo Netto, em um instigante estudo, esclarece que o autor da Ontologia do ser social, após a repressão soviética ao levante húngaro de 1956, tinha então como objetivo político "apoiar as medidas que parecem progressistas e democratizantes: [Lukács] definia sua postura no quadro húngaro como 'não oposição, mas reforma', sublinhando que o essencial era a solução da questão básica: a questão democrática" (2009, grifos nossos).

Como explica o cientista social brasileiro, Lukács chega nessa época ao "patamar mais alto" das reflexões políticas que ele denomina de democracia socialista, que acreditava ser a via para a "reconversão das sociedades soviéticas e do leste em formações societárias compatíveis com o projeto emancipador que animou o pensamento marxiano e marxista antes da sua perversão pelo dogmatismo e sectarismo" (Idem.). O velho filósofo húngaro estava convencido da possibilidade de uma auto-reforma dos países socialistas, onde se erradicaria o

\begin{tabular}{|c|l|l|l|l|}
\hline Govista Qialectus & Ano 2 & n.7 & Setembro-Dezembro 2015 & p. $35-47$ \\
\hline
\end{tabular}


stalinismo e se aprofundaria a crítica da sociedade burguesa. Possivelmente, o ensaio de Mészáros, escrito entre 1967 e 1968, no contexto da assim chamada "Primavera de Praga" que, em agosto de 1968, acabaria reprimida pelas tropas do Pacto de Varsóvia -, transite na órbita dos ideais então cultivados por seu mestre e amigo ${ }^{13}$.

Faltaria, ainda, de qualquer forma, a Mészáros o profundo estudo sobre os temas do capital e da transição que viria a ser realizado nas décadas seguintes e que culminaria politicamente com a proposta da revolução permanente desenvolvida em sua obra magna ${ }^{14}$.

\section{REFERÊNCIAS}

CHEROBINI, Demetrio. Educação e política no pensamento de István Mészáros: estudo introdutório. Florianópolis, SC: 2010. Dissertação (mestrado) - Universidade Federal de Santa Catarina, Centro de Ciências da Educação. Programa de Pós-Graduação em Educação.

MARTINS, José. Império do terror: Estados Unidos, ciclos econômicos e guerras no início do século XXI. São Paulo: Editora Instituto José Luís e Rosa Sundermann, 2005.

MÉSZÁROS, István. Para além do capital: rumo a uma teoria da transição. São Paulo: Boitempo, 2002.

MÉSZÁROS, István. A teoria da alienação em Marx. São Paulo: Boitempo, 2006.

MÉSZÁROS, István. O conceito de dialética em Lukács. $1^{a}$ ed. - São Paulo: Boitempo, 2013.

NETTO, José Paulo. Apresentação. In. O conceito de dialética em Lukács. $1^{\text {a }}$ ed. - São Paulo: Boitempo, 2013.

NETTO, José Paulo. Sobre Lukács e a política. PCB. Rio de Janeiro, 03 mar. 2011.

Disponível em:

<http://pcb.org.br/portal/index.php?option=com_content $\&$ view=article\&id=2426:sobre-

lukacs-e-a-politica. Acesso em 23/01/2014.

\footnotetext{
${ }^{13}$ Seria interessante observar, nesse sentido, as diferenças de posicionamento entre $O$ conceito de dialética em Lukács e uma das obras de Mészáros imediatamente posteriores, de 1970 (mas cuja redação começou em 1959 e foi finalizada em 1969, após, portanto, os decisivos acontecimentos de 1968), A teoria da alienação em Marx, que, parece-nos, se encaminha para uma posição política diversa, revolucionária - e não democratizante -, quando o filósofo húngaro teoriza sobre a questão da "transcendência positiva da auto-alienação do trabalho" (2006, p. 163-4). Essas questões todas, no entanto, carecem de uma investigação mais profunda e acurada, e que excedem as pretensões e limites deste artigo.

${ }^{14}$ Para além do capital, op. cit.
} 